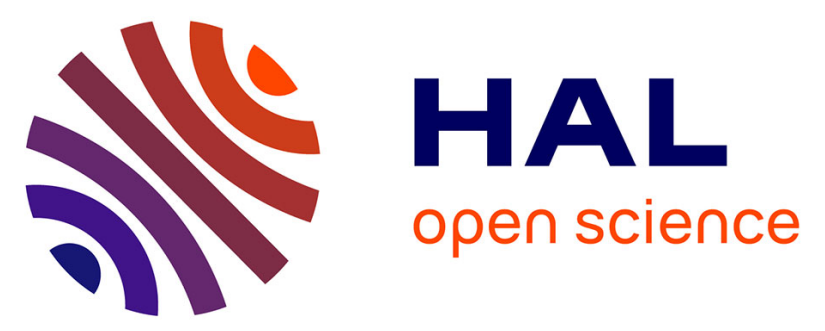

\title{
Evidence for farmers' active involvement in co-designing citrus cropping systems using an improved participatory method
}

\author{
Fabrice Le Bellec, Amelie Rajaud, Harry Ozier Lafontaine, Christian \\ Bockstaller, Eric Malezieux
}

\section{To cite this version:}

Fabrice Le Bellec, Amelie Rajaud, Harry Ozier Lafontaine, Christian Bockstaller, Eric Malezieux. Evidence for farmers' active involvement in co-designing citrus cropping systems using an improved participatory method. Agronomy for Sustainable Development, 2012, 32 (3), pp.703-714. 10.1007/s13593011-0070-9 . hal-00930548

\section{HAL Id: hal-00930548 \\ https://hal.science/hal-00930548}

Submitted on 1 Jan 2012

HAL is a multi-disciplinary open access archive for the deposit and dissemination of scientific research documents, whether they are published or not. The documents may come from teaching and research institutions in France or abroad, or from public or private research centers.
L'archive ouverte pluridisciplinaire HAL, est destinée au dépôt et à la diffusion de documents scientifiques de niveau recherche, publiés ou non, émanant des établissements d'enseignement et de recherche français ou étrangers, des laboratoires publics ou privés. 


\title{
Evidence for farmers' active involvement in co-designing citrus cropping systems using an improved participatory method
}

\author{
Fabrice Le Bellec • Amélie Rajaud • \\ Harry Ozier-Lafontaine • Christian Bockstaller • \\ Eric Malezieux
}

Accepted: 29 November 2011 / Published online: 30 December 2011

(C) INRA and Springer-Verlag, France 2011

\begin{abstract}
Agricultural policymakers are addressing the sustainable development issue by designing new agricultural systems. Farmers are ultimately asked to make deep changes at field scale. Designing cropping systems has previously been done using prototyping methodologies. Prototyping methodologies use a five-step designing process at field scale and request multicriteria analysis of the resulting prototypes. However, sustainable dynamics implies considering changes at larger scales, farm and region, as well as creating feedback and facilitating participation of all the stakeholders involved in the process. Here we studied citrus production in Guadeloupe, French West Indies, where farmers must reduce pesticide loads despite unresolved weed control issues. We designed the DISCS method, which stands for "participatory redesign and assess innovative cropping systems", to improve classical prototyping methods by implementing a multi-scale, multi-stakeholder, participatory approach. Compared to classical prototyping methods, the DISCS method differs by implementing three progress loops, at experimental field,
\end{abstract}

\section{F. Le Bellec $(\square) \cdot$ A. Rajaud}

CIRAD, UPR HortSys,

Station de Bassin Plat, B.P. 180, 97455 Saint-Pierre, France

e-mail: lebellec@cirad.fr

H. Ozier-Lafontaine

INRA, UR APC,

domaine de Duclos, Prise d'eau, 97170 Petit-Bourg,

Guadeloupe, France

C. Bockstaller

INRA, UMR1121 INPL/ENSAIA/INRA,

BP 20507, 68021 Colmar, France

E. Malezieux

CIRAD, UPR HortsSys,

TA B-103/PS4-Boulevard de la Lironde,

34398 Montpellier Cedex 5, France farm, and regional scales. Three categories of professional stakeholders are involved: farmers, researchers, and agricultural advisers, who are collectively in charge of designing and testing cropping system prototypes. In addition, local public stakeholders including representatives of state institutions are consulted. Progress is assessed using scale-specific sets of indicators. The DISCS method was applied to develop lowpesticide citrus cropping systems. Five weed control prototypes were jointly designed by citrus farmers and researchers, and two multicriteria assessment tools were built for use at the experimental station and on the farms. Results show that involved farmers transferred the new techniques to their own farms on their own initiative, thus spontaneously becoming pilot farmers. The DISCS method is therefore the result of a codesign process between farmers and researchers. The DISCS method creates an ongoing dynamic relationship between agricultural and public stakeholders to build a solution that can continuously be adjusted to stakeholders' expectations.

Keywords Participatory approach · Innovation . Multicriteria assessment $\cdot$ Cropping system · Guadeloupe (French West Indies) · Weed control · Decision-aid tool · Pesticides $\cdot$ DISCS

\section{Introduction}

As the "sustainable development" paradigm takes over the world, agricultural policy makers are responding by calling for more sustainable agricultural systems. In this context, redesigning cropping systems has become a major challenge for agricultural professionals, and for the last decade, agricultural researchers have been developing prototyping methods and tools to facilitate the design of innovative 
cropping and farming systems (Vereijken 1997). The task is challenging indeed: Innovation is expected to solve field scale constraints that originate at larger scales, at the end of a cascade of injunctions resulting from an initial call at planetary scale. In a nutshell, farmers are asked to make deep seated changes in their practices to address the global issue of world scale pollution. In return, changes made at field scale lead to "cascading effects" across scales of space and time, as well as across ecological, economic, and social domains (Kinzig et al. 2006). In this paper, we illustrate such top-down planning for sustainable agriculture with the case of citrus production in Guadeloupe (French West Indies). At French national scale, the State ruled that pesticide use must be reduced by 50\% before 2018 (Ecophyto 2008). This national objective is enforced by public agricultural counselors at regional scales, which means that, eventually, all Guadeloupian farmers will have to reduce their use of pesticides. The challenge of inventing adequate new cropping systems will be addressed later on in this paper, but for now, let us assume that all Guadeloupian citrus farmers do reduce their use of pesticides by $50 \%$. As a result, changes would also be expected in the whole farming system, in the quality of the fruit and in the pesticide industry. These could be a few of the "cascading effects" (Kinzig et al. 2006) that are mostly unpredictable but would nevertheless influence the general sustainability of the modified regional socioeconomic and agricultural landscape. This drives a need for dynamic, non-linear, multi-stakeholder, and transdisciplinary approaches (Veldkamp et al. 2009) to sustainable development, so as to preserve the structure, identity, and functions of a "social-ecological system" (Walker et al. 2004; Fig. 1).

In agriculture, prototyping methodologies usually draw on a well-tried step-by-step path for designing agricultural systems that has already been used in different approaches to developing sustainable farming systems (Lançon et al.

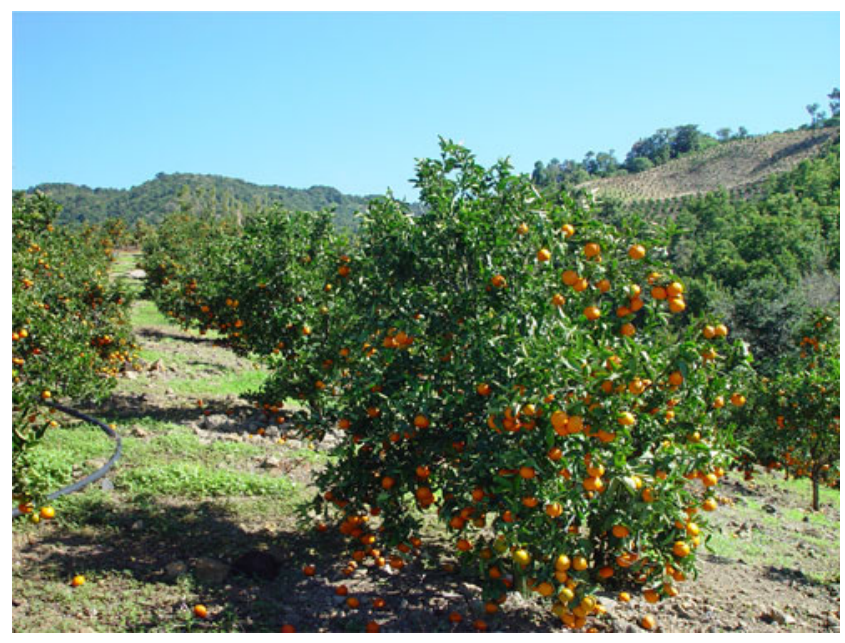

Fig. 1 Guadeloupian citrus orchard
2007; Sterk et al. 2007; Blazy et al. 2009). In this type of prototyping methodology, the goal for agronomists (and other scientists) is to produce a new complete arable farming system (Vereijken 1997) or cropping system (Lançon et al. 2007), which can be implemented on the farms after completion of a prototyping process. In addition, prototyping methods require multicriteria evaluation of innovative prototypes. To this end, several complex assessment tools based on a set of indicators have been developed for the assessment of practices at field scale (Bockstaller et al. 1997), at farm scale (Meul et al. 2008), and for ex ante assessment of cropping system prototypes (Sadok et al. 2009). The method for designing (Bockstaller and Girardin 2003) and validating (Cloquell-Ballester et al. 2006) assessment indicators has already been formalized. In these methodologies, farmers mainly play the role of consultants. However, sustainable dynamics implies considering changes at larger scales (farm and region) as well as creating feedback and facilitating the active participation of all the stakeholders involved in the process.

Reasons for adopting "participatory approaches" vary widely (Leeuwis 2000). On the one hand, ongoing learning among different stakeholders involved in an evolving system facilitates cross-scale feedback on changes in a system (Carpenter et al. 2001; Veldkamp et al. 2009) as well as negotiation when this is necessary (Rossing et al. 1997). On the other hand, involving end users of an invention or a tool in the design process should ensure the innovation is appropriate and ensure its appropriation (Cox 1996; Cardoso et al. 2001; Meynard et al. 2002). In recent years, calling for more involvement of farmers has become a leitmotif in reports on the design and assessment of decision support tools (King et al. 2000; Meynard et al. 2002; Lopez-Ridaura et al. 2002; Nolot and Debaeke 2003). King et al. (2000) highlighted the need for participatory processes enabling the joint definition of indicators by farmers and scientists, in order to (a) benefit from farmers' expertise and (b) give farmers ownership of the indicators. Nolot and Debaeke (2003) suggested that involving the producers in the process of building the indicators helps ensure the producers have confidence in the indicators' outputs.

Prototyping methodologies have therefore proved useful for designing new cropping systems, and multicriteria assessment tools have enabled full evaluation of innovative prototypes. However, transitions between scales (field to farm to region) are difficult to address using such approaches, mainly because the focus is on the agricultural problem at field scale and because farmers and non-agricultural stakeholders are not sufficiently involved. Here our aim was to adapt this prototyping method for use in a sustainable development process. The method was improved in three ways: (a) by involving farmers in the design process, (b) by involving public stakeholders and organizing communication and negotiation, and 
(c) by starting an ongoing dynamic process that corresponds to sustainable development.

The improved participatory re-design and assess innovative cropping systems (DISCS) method we present here was conceptualized and applied to the case of citrus production in Guadeloupe (French West Indies). As they are obliged to move toward a reduction of pesticides in accordance with French regulations (Ecophyto 2008), citrus producers face unresolved technical difficulties and are struggling to promote the quality of their products on the local market. The DISCS method was therefore used to develop more sustainable cropping systems based on reduced use of pesticides.

Such a method must be flexible enough to be used in different contexts and for different kinds of problems. While following the path set by the DISCS method, we gained insight into the potential generic extent of the methodological choices that were made at each step of the ongoing process in this case study.

\section{Material and method}

In this section, we first present the DISCS method and then describe how it was applied to Guadeloupian citrus production.

\subsection{DISCS method}

With the DISCS method, the aim is not to design a whole new cropping system but rather to focus on one key aspect that needs improving and to proceed by involving the stakeholders who may eventually be affected by changes in agricultural practices. The DISCS method we describe here is part of the family of prototyping methods defined by
Vereijken (1997). The original five-step method proposed by Vereijken (1997) was followed, with some modifications. In Vereijken's original method, first, a hierarchy of objectives is established; second, the objectives are transformed into a set of multi-objective parameters and methods to achieve them; third, a theoretical prototype is designed; and fourth, tested and improved. The fifth step consists in the dissemination of the prototype, which is expected to take place by diffusion from a group of pilot farms to other farms in the area (Vereijken 1997). The DISCS method goes beyond Vereijken (1997) by explicitly organizing collaborative work between different categories of stakeholders and by introducing loops of iterative, gradual improvement, at steps 3, 4, and 5 (see Fig. 2).

In our method, four categories of stakeholders are involved: first, farmers, who are the initial and final designers as well as being responsible for and involved in daily agricultural practice; second, researchers, who provide scientific knowledge and conceptualize methods and tools; and third, agricultural advisers, who provide local technical knowledge and transfer scientific results to farmers. We refer to these three categories combined as "professional stakeholders." The fourth category comprises stakeholders who are not involved in agriculture by profession but are part of the regional socioecological system, are concerned by the general orientation of regional development, and may be affected by changes resulting from modifications made at field scale. "Public stakeholders" include representatives of the State and regional institutions and representatives of civil organizations, as well as of the agricultural sector. In the DISCS approach, all stakeholders (whether public or professional) are involved at the local scale: They all gather for public meetings, at which smaller groups are extracted to attend more specific workshops.
Fig. 2 Prototyping steps. The DISCS method follows the same path as the original method (Vereijken 1997) but involves four categories of stakeholders

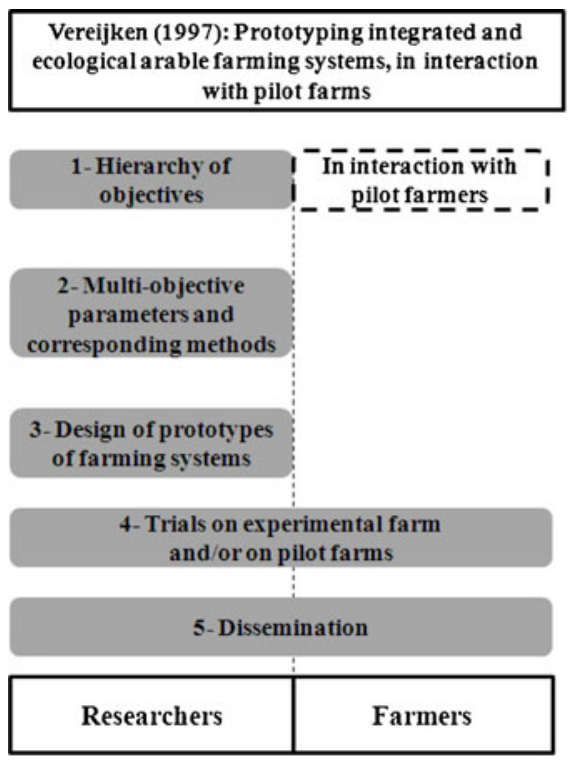

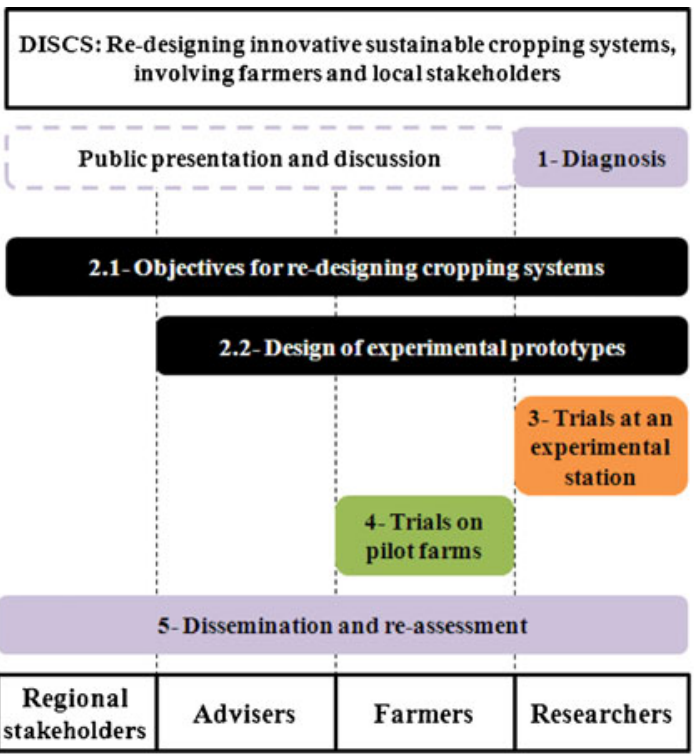


The diagnosis in step 1 has a dual aim: First, to analyze the existing agronomical situation and, second, to generate multi-stakeholder interactions. Before engaging in the actual prototyping process at field scale, step 1 is implemented at regional scale, so that all public stakeholders can express their points of view on and interests. When the results of the diagnosis are presented to the community, feedback from the many different stakeholders may finally lead to their sharing a common analysis of the situation.

Step 2 is the transition from regional scale public debate about regional issues, to field scale planning for the design of innovative cropping system prototypes. Accordingly, step 2 is split into two sub-steps. A first workshop is organized during which representatives of public and professional stakeholders negotiate the objectives for re-designing cropping systems, capitalizing on the results of the diagnosis. Later on, professional stakeholders only meet to collectively design suitable "experimental prototypes" for cropping systems that integrate innovative techniques.

In step 3, the prototypes are implemented and tested by researchers at an experimental station. When they have been validated, the selected prototypes are "transferred" to pilot farmers and adjusted to existing farming systems, at step 4. A to-and-fro movement between steps 3 and 4 (see Fig. 3) continues until a new cropping system has been characterized and validated by the researchers and the farmers and put into practice on the farms.
Finally, the effect of changing practices at farm scale is evaluated at regional scale, and the results are presented to public stakeholders, at step 5. A new regional diagnosis is then performed to re-orientate the ongoing dynamics at this scale. The challenge is to continuously take action at field scale in response to continuous developments at regional scale.

The innovative prototypes are evaluated at each step. Multicriteria assessment tools are designed to account for different and possibly conflicting objectives. Here, three distinct evaluations are required. Ad hoc assessment tools are designed by the researchers, but the process should involve their end users to facilitate their appropriation.

Different users need different assessment tools. These tools may differ in nature (i.e., all the assessment criteria will not be appropriate at each scale) and in the level of aggregation (when more or less detailed information is needed at different scales) (Stein et al. 2001). At the scale of the experimental station (step 3), the assessment indicators that comprise the monitoring tool may support a high level of complexity and require a lot of precise input data. However, at regional scale (step 5), the tool's indicators need to provide information that can be understood by public stakeholders. While they may support a lower level of technical acuity, they should offer a straightforward comparison of different possible technical pathways to achieve ecologically and socioeconomically sustainable objectives. These are indicators with a high level of aggregation. At farm scale (step 4), the monitoring tool is a decision-aid tool for
Fig. 3 The DISCS method. Steps 3, 4, and 5 consist of progress loops running at the same time. Between the research experiments and the on-farm trials, a to-and-fro movement enables continual adjustment of the prototypes $(a)$

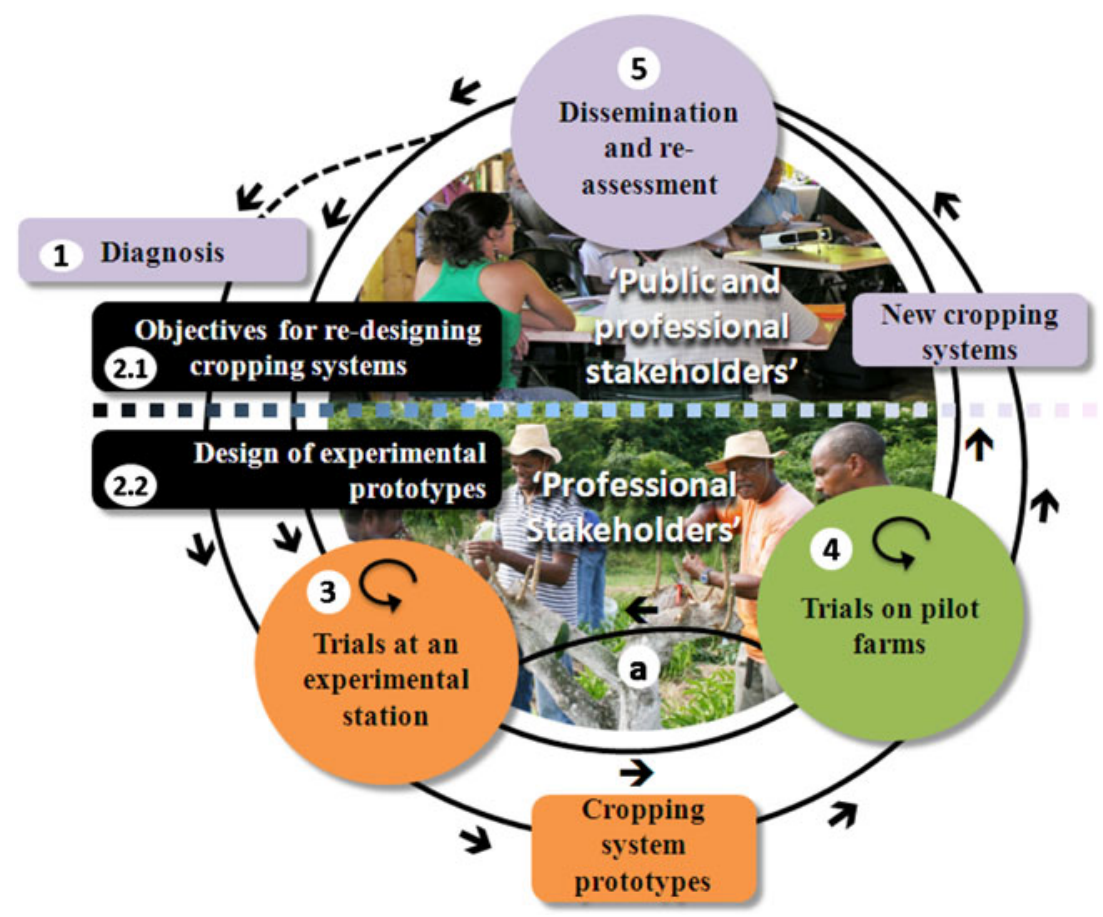


farmers. The indicators require a balance between accuracy and ease of use.

\subsection{Case study}

The DISCS method was used to address the Guadeloupian citrus production issue. Applying this method implied making methodological choices which depended on the specific context and the means available. During the implementation process, the "material" used at each step (specially designed prototypes and assessment tools, the composition of the stakeholders' workshops) had been produced during preceding steps. The "material" we present in this section is thus strictly limited to the overall implementation of the method. Material that resulted from the ongoing innovation process will only be presented (as we progress) in the "Results of the case study and discussion" section.

In the 2007-2013 Guadeloupe rural development program, upport for the citrus industry is a priority to enable the local demand for citrus fruits to be satisfied, this market currently mostly being covered by imports. This requires producers to reduce the use of pesticides, in accordance with French objectives (Ecophyto 2008). This ruling was introduced at a time when citrus producers are still facing unresolved technical difficulties and are struggling to promote the quality of their products on the local market. The main concern in re-designing citrus cropping systems is therefore to develop lower-input cropping systems with improved economic and quality performances, in a move toward sustainable citrus production in Guadeloupe.

Public stakeholders are represented by agents from State administrations, Guadeloupe's National park and local associations. The research team works at CIRAD's experimental station in Vieux-Habitant, in the citrus production area on the west coast of Guadeloupe, $16^{\circ} \mathrm{N}, 61^{\circ} \mathrm{W}$, where experiments on tropical fruit cropping systems are performed. Finally, regional citrus producers were classified according to their farming systems. Based on a survey of 41 citrus producers interviewed by a research team in 2006, a typology of farming systems was established: For the "citrus growers" category, growing citrus fruits is the main or only activity; "dual producers" have two main agricultural activities, citrus being the second crop; "diversified producers" have at least three agricultural activities, with citrus as one diversification crop among others (Le Bellec et al. 2011).

\subsubsection{Step 1. Diagnosis}

The diagnosis was performed by researchers. The aim was to identify the farming strategies that citrus growers use and the constraints they face. An original typology of cropping practices was based on comparison with a reference crop management (RCM) that had been diffused to all citrus growers a few years earlier. This method of diagnosis was chosen to assess the relevance and the performance of the RCM, while revealing the main constraints facing citrus growers that the RCM had failed to solve. The original method is presented in a companion paper (Le Bellec et al. 2011).

The RCM covers five main combinations of cropping practices. For every farm visited, the survey evaluated whether the reference crop management was respected for each of the five combinations of cropping practices. In addition, two levels of performance were expected from citrus crop management: (a) to reduce pesticide use and (b) to improve the yield and the quality of the fruit. At each orchard visited, these two performance criteria were evaluated using two indicators: (a) the indicator used by the State services, treatment frequency index (TFI), was chosen to evaluate the level of pesticide use and (b) a visual estimation of the state of health of the trees accounted for the potential profitability of a tree. Step 1 ended with a progress meeting that assembled professional and public stakeholders during which the results of the diagnosis were presented.

\subsubsection{Step 2. Objectives, assessment criteria, and design of the prototypes}

Two workshops were held, one only with professional stakeholder and the other with a group of public stakeholders. The mandate of the participants in the "professional" workshop was to focus on the design of cropping system prototypes. It included three producers, each representing one type of citrus farmer (according to the established typology of farming systems), one local agricultural adviser, and two agronomical researchers from the local experimental station. The public workshop was extended to include representatives of all public stakeholders, including stakeholders from the professional workshop. The aim was to establish objectives for the new cropping systems based on an integrated regional perspective. While all members of a workshop were originally invited by the research team, it was then up to invited members to complete attendance through a co-optation process.

\subsubsection{Step 3. Research loop}

Experiments were performed by the research team at the local experimental station. Testing and adjusting the experimental prototypes followed a plan-do-check-act process.

An ad hoc assessment tool for evaluating the performance of the prototypes was designed by researchers. To validate the performance objectives chosen at step 2 compared with 
existing cropping systems, the observed results then underwent multicriteria analysis using the specially designed assessment tool.

\subsubsection{Step 4. Development loop}

The design of the decision-aid tool was directed by the research team, but an attempt was made to extend the design team to other "professional" stakeholders. Following the proposal of Bockstaller et al. (1997), all step 4's indicators were designed to display a score ranging from 0 to 10 , in order to make the performance of each indicator easy to understand, while the homogeneous display makes the results of different indicators easy to compare.

The researchers were the designers of this assessment tool. However, they presented some of the indicators at a technical workshop that included final users of the tool. Selected indicators were thus either presented to their final users, or subject to collective debate and correction.

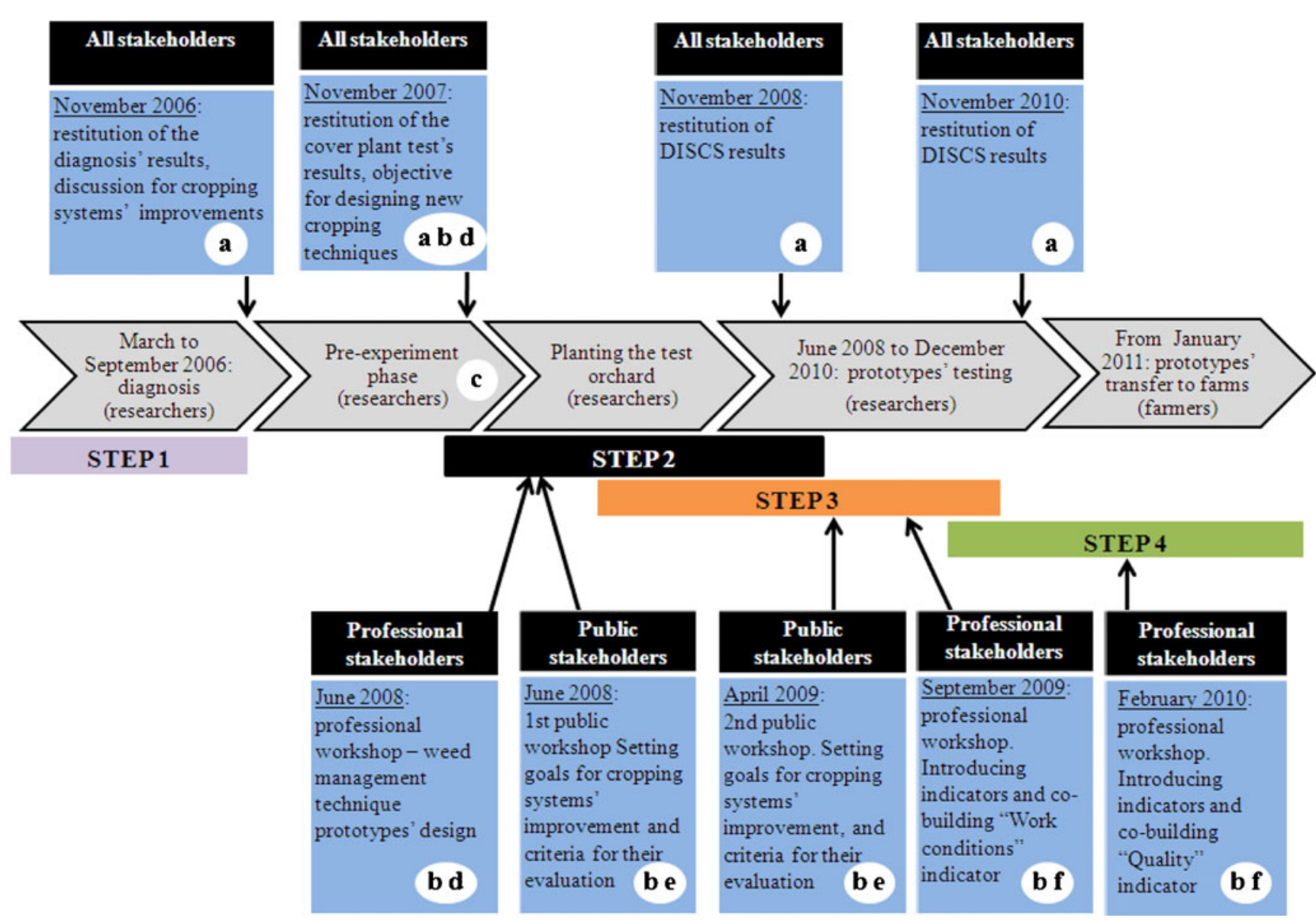

Fig. 4 Chronology of the re-design of citrus production using the DISCS method. Public and agricultural stakeholders were involved during progress meetings $(a)$ and participatory workshops $(b)$. A preliminary diagnosis was needed before designing the prototypes

\section{Results of the case study and discussion}

The DISCS process was set in motion in 2006 and is still running at the time of writing (2011); its chronology is detailed in Fig. 4.

3.1 Step 1. Diagnosis: comparing farmers' practices with a reference crop management

The results of the initial diagnosis are detailed in Le Bellec et al. (2011). The diagnosis concluded that the two main technical constraints that needed to be overcome to improve Guadeloupian citrus cropping systems were (a) the fact that many fields cannot be mechanized due to steep slopes and stony soils and (b) the lack of producers' specific skills concerning the use of chemical products in the management of the orchards. According to these results, it was collectively agreed to focus the redesign process on developing an alternative low-input weed control that is compatible with the impossibility to mechanize. (c). Step 2 started after the diagnosis $(d)$ and continued when step 3 had already begun, to sort out assessment criteria (e). Step 4 started with the design of the farmers' decision-aid tool while step 3 was still running $(f)$ 
The leading stakeholders at this step were the researchers who collected and analyzed field knowledge. Step 1 concluded with a progress meeting in November 2006, attended by 50 professional and public stakeholders, when the results of the diagnosis were presented (Fig. 4). Public (agents from State, regional, and civil institutions and organizations) and professional (farmers who had been interviewed, local agricultural advisers, and researchers from local institutes) stakeholders attended this progress meeting. Presentation of the results enabled all the participants to reach a common understanding of regional stakes and local field constraints. This was important for later on convincing stakeholders to participate in workshops organized during subsequent steps. This method of diagnosis was successful in highlighting a key aspect of local cropping systems that could be the first focus of a step-by-step redesign process. However, this method of diagnosis is limited to contexts where a RCM has already been diffused. With a view to further agronomical diagnoses, more participatory methods could be used (e.g., Girard 2006), which would enable finer analyses of cropping practices. However, a balance must be found between the need to prepare a solid basis for an appropriate innovation process and the need to get started.

\subsection{Step 2. Objectives, assessment criteria, and design of the prototypes}

The actual design started at step 2. To enable collective work, a limited number of different stakeholders were invited to attend workshops. However, in the meantime, at the researchers' initiative, preliminary research had been conducted on the feasibility of solving the mechanization problem by planting a ground cover as a weed control strategy. A second public progress meeting was held in November 2007, when the researchers presented their research results as a possible answer to the redesigning issue (Fig. 4).

In June 2008, a "professional workshop" and a "public workshop" were held. When the professional workshop met, the technical constraints that had been identified by the diagnosis (step 1) were discussed again and transformed into five sub-objectives for the experimental prototypes: (a) controlling soil erosion, (b) reducing the need for pesticides, (c) reducing the impact of pesticides, (d) maintaining good yields, and (e) achieving reasonable water use. The five experimental prototypes that were collectively designed differed in ground cover management techniques: One prototype involved the systematic use of a herbicide (prototype GLY); two prototypes involved managing weeds using a spontaneous plant cover, either perennial (prototype PV) or annual (prototype AV); and two prototypes involved sowing a ground cover plant, again perennial (prototype PNeo) or annual (prototype ANeo). Control prototype GLY accounted for the citrus producers' current practices and set the reference for future assessment and comparison of the prototypes. Prototype PV was the reference crop management (Le Bellec et al. 2011).

The public workshop originally included, at the research team's invitation, a farmer, an adviser, and a researcher who had attended the professional workshop, along with a consumer, a member of the public administration, and an agent from the National Park. During this public workshop, the sub-objectives defined during the professional workshop were validated. In addition, considering the wider regional perspective, three complementary sub-objectives were added to improve the new cropping systems at farm scale. These were ( $\mathrm{f}$ ) reasonable energy use, $(\mathrm{g})$ ensuring profitability, and (h) maintaining a social balance. Moreover, the participants felt the need to address the quality aspects of fruit production. They consequently co-opted two more participants (a salesman and a health professional) to the workshop. For these reasons, a second public workshop was convened a few months later, in April 2009. The new focus on the quality aspect led to adding a quality and security indicator to the list. This criterion was subsequently revealed to be particularly important, as it helped focus on the economic value of citrus production. This "quality" criterion provided matter for a debate that involved every single stakeholder. The final list of sub-objectives and criteria for evaluating the experimental prototypes (step 3) and the new cropping systems (step 4) was only completed during the second meeting of the public workshop, after step 3 had started. Table 1 lists the sub-objectives. The corresponding assessment indicators were chosen or designed at steps 3 and 4.

DISCS's fundamental principle is to proceed step by step and to only develop innovative proposals that producers are willing to test in their own fields. The local approach used in our case study proved to be effective as it led to the immediate appropriation of the suggested innovative techniques (discussed in the following sections) by local farmers. However, other approaches to the design of prototypes may call for experts who are external to the regional system (Lançon et al. 2007): This may ensure that newer or more inventive prototypes are designed. While the possibility of calling on international experts or using models to design innovations should not be overlooked, we recommend it be done only after a local multi-stakeholder dynamics have been created.

3.3 Step 3. Research loop: trials and multicriteria analysis of the experimental prototypes

At this step, researchers took over experiments on the prototypes. A multicriteria assessment tool was built by the research team according to the guidelines defined at step 2. It included seven composite indicators; each one of which was either selected or specially designed for evaluation at 


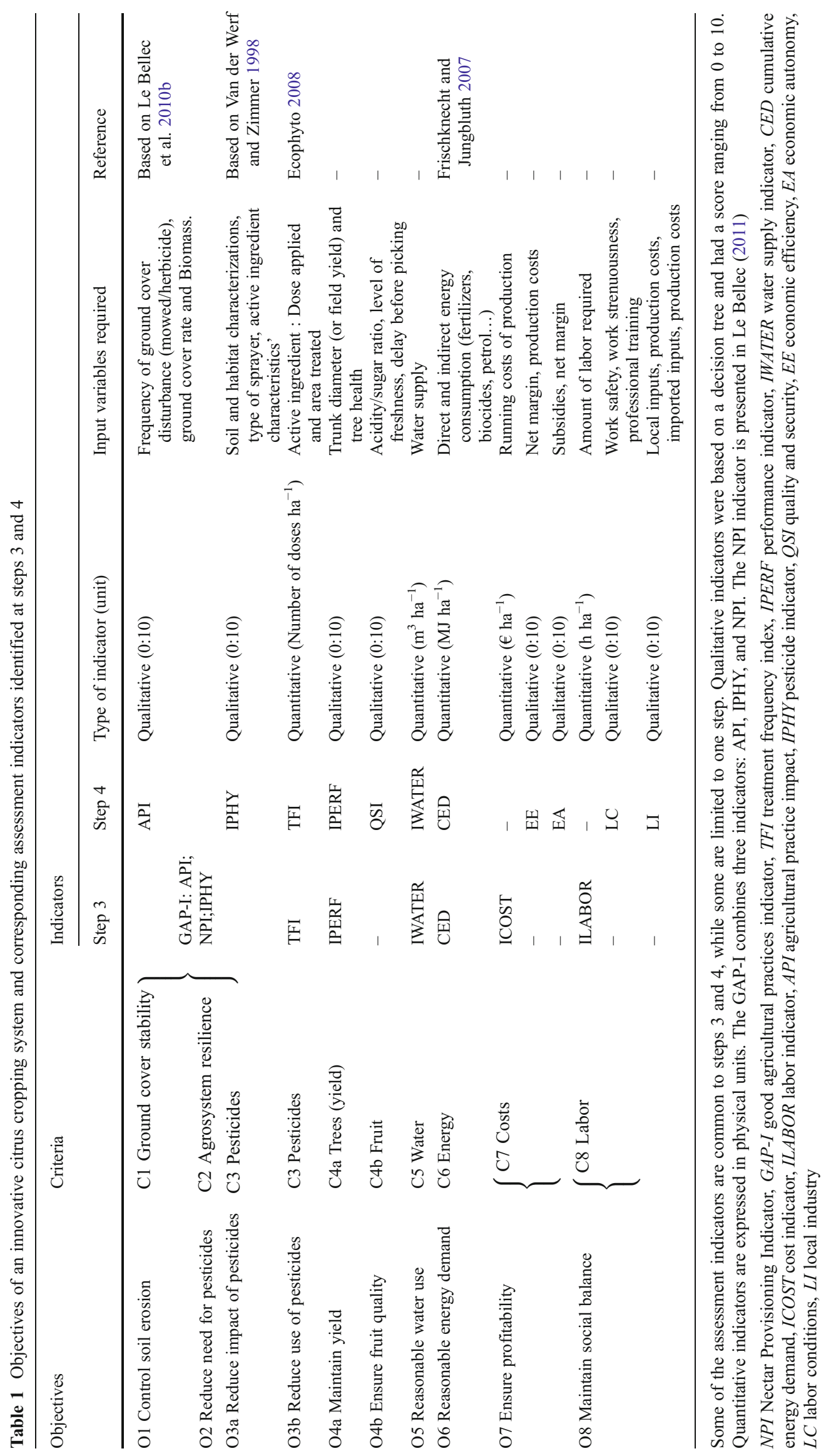


step 3 (see Table 1, column "step 3"). The characteristics of the indicators are listed in Table 1. For objectives 7 and 8 (Table 1), two indicators (ICOST and ILABOR, respectively costs and labor indicators) were added to balance the evaluations at steps 3 and 4 . Although this step was managed by the researchers, validation and selection of the best prototypes also involved the farmers. Consequently, the assessment tool for step 3 was designed to assess performances and to provide farmers with a comparative analysis to enable them to make a well-informed choice at step 4.

A detailed analysis of the results of step 3 and the building of assessment indicators is presented in Le Bellec (2011). Based on the results of a previous study (Le Bellec et al. 2010a), Neonotonia wightii Wight and Arnott (Fabaceae) was selected as a perennial ground cover plant for weed control without mechanization. All five prototypes were repeated five times, tested, and compared in a young orchard (planted in January 2008) from August 2008 to December 2010. The five prototypes complied with the reference crop management and only differed with respect to weed control. The expected impacts were then monitored using the multicriteria assessment tool.

All three experimental prototypes had advantages and drawbacks. AV performed better in terms of growth and water needs in young orchards. Moreover, being close to the "reference practice" recommended by the reference crop management, one main advantage of AV was its limited need for new investment. Several farmers expressed interest in implementing this weed control technique in their orchards. PNeo enabled weed control without the use of herbicides. Despite PNeo's poor IPERF result, the competition between the cover plant and young trees could be avoided by only planting it in adult orchards (based on results in Le Bellec et al. (2010a)). Finally, despite the fact that ANeo had the second highest TFI (pesticide indicator) value, it achieved acceptable good agricultural practices indicator and performance indicator results and had the lowest cost indicator and labor indicator values (Table 2).

The final indicators were presented to an assembly of public and professional stakeholders in November 2010 (Fig. 4). Comparative analysis of the prototypes led the researchers to identify and present prototype ANeo as the best alternative to current practice (GLY). The indicators used by the researchers at this step supported a high level of complexity and required a lot of precise input data, which were available at the experimental station. The resulting analytical grid proved to be a good support for the researchers to explain the prototypes' comparative strengths and weaknesses to a large mixed public and professional audience. On the other hand, informal exchanges between the researchers and a small group of around ten local citrus growers had already taken place at the experimental station. Here, the strong local integration of the experimental research station should be highlighted. Even though the experiments were only conducted by researchers, communication with farmers continued while the experiments were underway. The station was open to visits and farmers were able to follow the progress of the trials. This explains the growing interest in the cover plant alternative for weed control expressed by some producers, even before the end of trials.

3.4 Step 4. Development loop: design of a decision-aid tool for farmers

The research team first designed a ten-indicator-assessment tool, based on the criteria selected during the public workshop at step 2. Two out these ten indicators were submitted to group consultation during technical workshops. The two successive

Table 2 Characteristics and performance of the five experimental prototypes at step 3 performed in the citrus orchard trial (Guadeloupe, August 2008 to December 2010)

\begin{tabular}{|c|c|c|c|c|c|c|c|c|}
\hline \multirow[t]{2}{*}{ Weed control prototypes } & \multirow[t]{2}{*}{ Type of vegetation } & \multicolumn{7}{|l|}{ Indicators } \\
\hline & & $\begin{array}{l}\text { GAP-I } \\
(0 \text { to } 10)\end{array}$ & $\begin{array}{l}\text { TFI (number } \\
\text { of doses) }\end{array}$ & $\begin{array}{l}\text { IPERF } \\
(0 \text { to } 10)\end{array}$ & $\begin{array}{l}\text { IWATER } \\
\left(\mathrm{m}^{3}\right)\end{array}$ & $\begin{array}{l}\text { CED } \\
(\mathrm{MJ})\end{array}$ & $\begin{array}{l}\text { ICOST } \\
(€)\end{array}$ & $\begin{array}{l}\text { ILABOR } \\
\text { (h) }\end{array}$ \\
\hline PV mowed $\left(3\right.$ years $\left.^{-1}\right)$ "reference practice" & Spontaneous & 5.3 & 3.2 & 5 & 5,500 & 13,633 & 1,919 & 126 \\
\hline $\begin{array}{l}\text { GLY: annual vegetation herbicides } \\
\text { (whole } \mathrm{S}^{2}, 3 \text { year }^{-1} \text { ) "current practice" }\end{array}$ & Spontaneous & 3.4 & 5.6 & 10 & 4,900 & 7,566 & 1,143 & 60 \\
\hline $\begin{array}{l}\text { AV mowed }\left(3 \text { years }^{-1}\right) \text { herbicides } \\
\left(\text { whole } S^{2}, 1 \text { year }^{-1}\right)\end{array}$ & Spontaneous & 5.0 & 3.2 & 8.4 & 5,355 & 12,300 & 1,875 & 128 \\
\hline $\begin{array}{l}\text { ANeo: annual vegetation herbicides } \\
\text { (whole } S^{2}, 1 \text { year }^{-1} \text { ) }\end{array}$ & $\begin{array}{l}\text { Planted with Neonotonia } \\
\text { wightii }\end{array}$ & 6.9 & 4.3 & 7.2 & 5,490 & 6,733 & 1,017 & 41 \\
\hline $\begin{array}{l}\text { PNeo: perennial vegetation hand } \\
\text { management }\end{array}$ & $\begin{array}{l}\text { Planted with Neonotonia } \\
\text { wightii }\end{array}$ & 7.0 & 1.3 & 3 & 5,825 & 5,066 & 2,069 & 199 \\
\hline
\end{tabular}

GAP-I and IPERF: means from the experimental period (August 2008 to December 2010); other indicators: means per hectare per year. N. wightii was selected as a ground cover plant during preliminary research

GAP-I good agricultural practices indicator, TFI treatment frequency index, IPERF performance indicator, $C E D$ cumulative energy demand, $P V$ perennial vegetation, $A V$ annual vegetation 
workshops included ten citrus growers, two researchers, and one agricultural adviser. One indicator, pesticide indicator (IPHY), was merely presented and explained by the researchers. The second indicator, labor conditions (LC), was the subject of collective discussion and adjustment.

Figure 5 shows how the initial structure of LC indicator changed following agreements reached during this workshop. The LC indicator remained the subject of discussion for several days, attesting to the involvement of the farmers, whereas the IPHY indicator elicited no additional comments. We interpreted the difference in the farmers' attitude to the two indicators as a beginning of appropriation of the LC indicator by farmers that was facilitated by their involvement in the design of the indicator. Such a result corroborates the recommendations of other authors for the collective design of decision support indicators (King et al. 2000). Although it may not appear reasonable to co-design all the indicators required, when developing decision-aid tools, we recommend considering collective design as often as possible. In the present case, for instance, converting IWATER and CED into qualitative indicators (which implies setting meaningful reference values) will be done collectively.

The set of indicators used for the present study is still incomplete. The existing set will be extended during the course of the innovation process, and as the technical issues become more and more clear-cut, the selection of existing indicators and their need for adjustment to the specific context will be clarified. The indicators that were developed for the present study may be useful in other contexts, but they would almost certainly need to be adapted.

In the further development of the DISCS farmer targeted decision-aid tool, two aggregation levels will be introduced to give users both an overview of the performance of a cropping system and to enable them to focus on the details of certain aspects (Meul et al. 2008). One "display level" will summarize the performances of a cropping system with respect to the goals set at step 2. At the second level, an "interpretation level," the variables will be less aggregated so that points that require more action to improve their performance will be apparent.

\subsubsection{Spontaneous appropriation}

Even before the end of the experimental trials (step 3), the PNeo prototype was put into practice by one citrus farmer in 2008. His positive feedback concerning the efficiency of the cover plant for weed control and the apparent lack of impact on fruit yield after 2 years encouraged two more citrus farmers to plant $N$. wightii as a ground cover before the end of 2010. It is remarkable that all three producers belonged to the "citrus growers" category in the farm typology (step 1), i.e., those most involved in citrus production. Moreover, the first producer to implement PNeo had participated in the "professional workshop" at step 2, while one of the other two farmers had attended the indicator co-designing workshop at step 4. All three producers had attended annual report

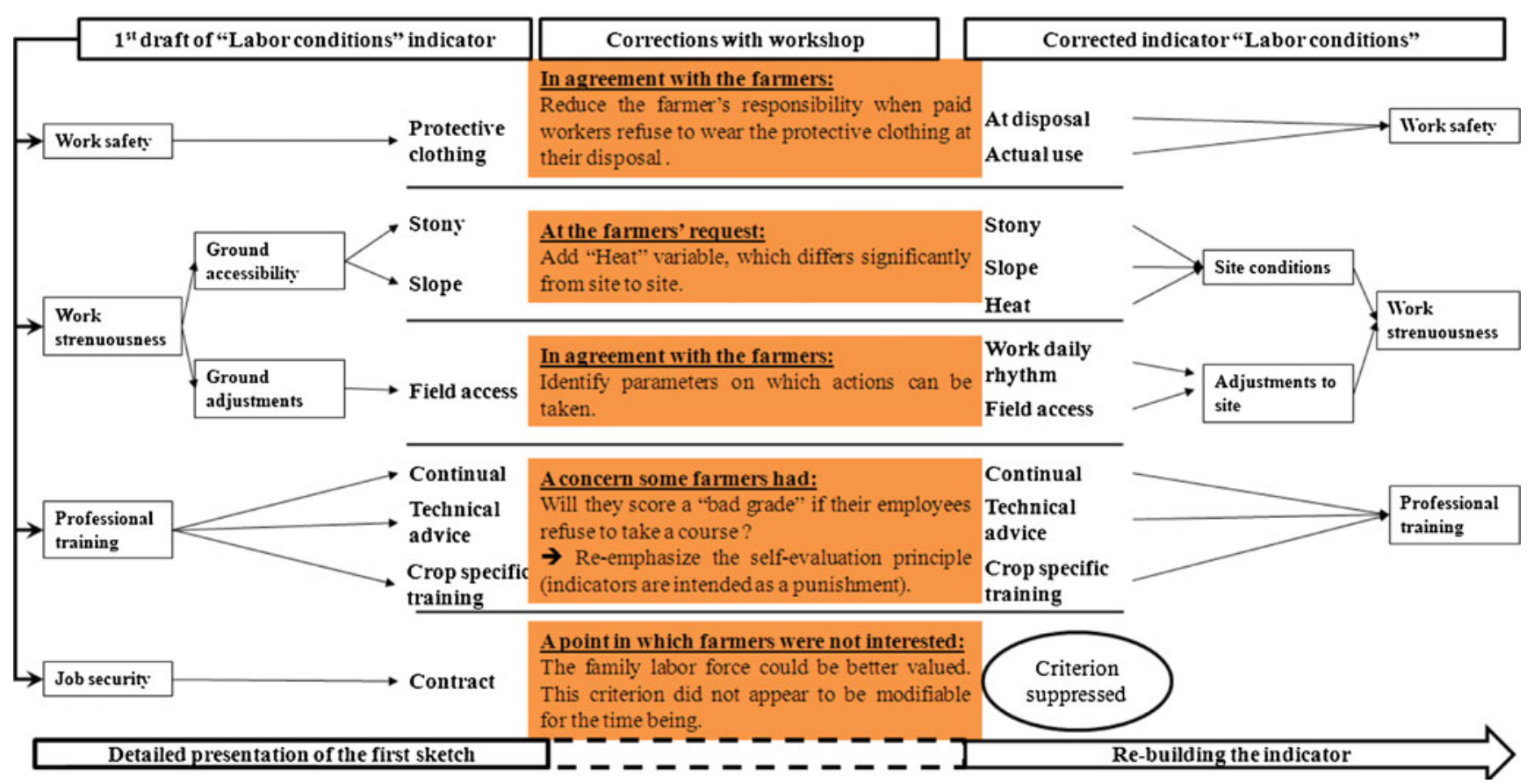

Fig. 5 Co-building the labor conditions indicator. An initial selection and organization of field accessible criteria was performed by the researchers. This result was presented to a group of ten farmers: selected criteria, missing criteria, reference values, and the hierarchy of the criteria were discussed. A new farmers-researchers workshop is planned to validate the final aggregation performed by the researchers 
meetings and visited the trials at the experimental station (step 3 ). This not only emphasizes the positive effect of involving the producers in the design (already demonstrated by other approaches, e.g., Cardoso et al. 2001) but also the efficiency of the demonstration on "pilot" farms in motivating other farmers.

\subsection{Toward step 5}

Only when the cropping systems of the farmers involved in the project have been adapted to include new cropping practices can they be considered as innovative cropping systems. Further transfer to farmers who are not involved in the project occurs either by diffusion or by extending the pilot farmer network. Feedback from the case study was not available at the time of writing. But, as explained at step 4, we expect the characterization and improvement of fruit quality to be the next urgent problem to be addressed in this researcher-farmer innovation process. It is necessary that a process coordinator be designated. This coordinator can then legitimately decide to proceed with a new regional diagnosis and evaluation when he or she considers that the innovation has been well implemented in the region. In the present case study, a researcher played this role, and he benefited from having an overview of the innovation process at each stage of the process. However, the coordinator can be any stakeholder who is involved. An alternative way to determine the right time to introduce a new innovation progress loop would be after a periodic (annual) regional evaluation, but this appears to be too demanding to be feasible.

\section{Conclusion}

The DISCS method mainly relies on the mobilization and coordination/animation of a network of different stakeholders, who are involved at different steps and to different extents. This is both the main strength and a major difficulty involved in achieving a sustainable innovation process. Involving a wide range of local stakeholders implies finding compromises between the main interests of different stakeholders (whether abolishing the use of pesticides, or improving the economic value of the product, or addressing a major phytosanitary issue). Besides, the inevitable delays associated with organizing meetings of stakeholders may slow down the process. The difficulty is also for a (local) research team to address issues related to a wide range of disciplines: In the present case, the same team would not be able to address the quality issue alone.

On the other hand, involving farmers from the beginning of the process certainly facilitated the diffusion of new techniques. An additional benefit of this multi-stakeholder approach was the emergence of a local dynamics that facilitated dialogue and mutual learning and that we believe will enable the innovation process to continue, new issues to be tackled, and maybe to give a bigger role to other stakeholders, for instance in valorizing the quality of local fruits.

Finally, in contrast to the classic "top-down" approach to agricultural innovation, i.e., researchers innovate, farmers put into practice - the DISCS method is a farmer-researcher co-design process that creates the conditions for an ongoing dynamic relationship between agricultural and public stakeholders to build a solution that can continuously be adjusted to stakeholders' expectations. Nevertheless, a transfer does take place from researchers to farmers, but rather than an "innovation transfer," it would be more appropriate to call it "innovation process transfer." DISCS is therefore a suitable method for improving an existing reference cropping system or current practices. Further research is needed to improve the tools used for environmental diagnosis (Meynard et al. 2002), to design indicators of fruit quality and to design crop models that are suited to local contexts. Yet, as it stands, the DISCS method should enable stakeholders to choose the right decision-aid tools to solve a specific problem and to ensure that the tools they have chosen are useful when and where they are actually needed, rather than searching a posteriori for possible applications for new tools (Cox 1996).

Acknowledgments We would like to express our warm thanks to all the producers, technicians, and other stakeholders of the citrus growing sector in Guadeloupe for their involvement in this study. This work was financially supported by the European Union (EAFRD) and the French office for the development of the agricultural economy of French overseas departments (ODEADOM). We are grateful to two anonymous reviewers for their valuable insight on this paper.

\section{References}

Blazy JM, Ozier-Lafontaine H, Doré T, Thomas A, Wery J (2009) A methodological framework that accounts for farm diversity in the prototyping of crop management systems. Application to bananabased systems in Guadeloupe. Agric Systems 101:30-41

Bockstaller C, Girardin P (2003) How to validate environmental indicators. Agric Systems 76:639-653

Bockstaller C, Girardin P, van der Werf HMG (1997) Use of agroecological indicators for the evaluation of farming systems. Eur $\mathrm{J}$ Agron 7:261-270

Cardoso IM, Guijt I, Franco FS, Carvalho AF, Ferreira Neto PS (2001) Continual learning for agroforestry system design: university, NGO and farmer partnership in Minas Gerais, Brazil. Agric Systems 69:235-257

Carpenter S, Walker B, Anderies JM, Abel N (2001) From metaphor to measurement: resilience of what to what? Ecosystems 4:765-781

Cloquell-Ballester VA, Cloquell-Ballester VA, Monterde-Diaz R, Santamarina-Siurana MC (2006) Indicators validation for the improvement of environmental and social impact quantitative assessment. Environ Impact Assess Rev 26(1):79-105

Cox PG (1996) Some issues in the design of agricultural decision support systems. Agric Systems 52:355-381 
Ecophyto 2018 (2008) http://agriculture.gouv.fr/ecophyto-2018. Accessed Jun 2011

Frischknecht R, Jungbluth N (2007) Implementation of life cycle impact assessment methods - Ecoinvent data v2.0. Swiss center for life cycle inventories (ecoinvent), Dübendorf, ecoinvent report $3,32-38$

Girard N (2006) Catégoriser les pratiques d'agriculteurs pour reformuler un problème en partenariat - Une proposition méthodologique. Cah Agric 15:261-272

King C, Gunton J, Freebairn D, Coutts J, Webb I (2000) The sustainability indicator industry: where to from here? A focus group study to explore the potential of farmer participation in the development of indicators. Aust J Exp Agr 40:631-642

Kinzig AP, Ryan P, Etienne M, Allison H, Elmqvist T, Walker BH (2006) Resilience and regime shifts: assessing cascading effects. Ecol Soc 11(1):20

Lançon J, Wery J, Rapidel B, Angokaye M, Gérardeaux E, Gaborel C, Ballo D, Fadegnon B (2007) An improved methodology for integrated crop management systems. Agron Sust Dev 27: $101-110$

Le Bellec F, Damas O, Boullenger G, Tournebize R, Vannière H, Ozier Lafontaine H, Jannoyer M (2010a) Weed control with a cover crop (Neonotonia wightii) in orchards in Guadeloupe (FWI). 28th International Horticultural Congress, August 22 27, 2010, Lisboa

Le Bellec F, Mailloux J, Dubois P, Rajaud A, Kreiter S, Bockstaller C, Tixier MS, Malézieux E (2010b) Phytoseiid mites (Acari) are bioindicators of agricultural practice impact on the agroecosystem functioning: the case of weed management in citrus orchards. In: Wery J, Shili-Touzi I, Perrin A (eds) Proceedings of Agro 2010: the XIth ESA Congress, August 29th-September 3rd, 2010. Montpellier, France

Le Bellec F (2011) Reconception et évaluation des systémes de culture - Le cas de la gestion de l'enherbement en vergers d'agrumes en Guadeloupe. Thèse de doctorat en sciences de la vie. Université Antilles-Guyane, Guadeloupe, France, 289 pp

Le Bellec F, Cattan P, Bonin M, Rajaud A (2011) Building a typology of cropping practices from comparison to a common reference: first step for a relevant cropping system re-designing processresults for tropical citrus production. Fruits 66:143-159
Leeuwis C (2000) Reconceptualizing participation for sustainable rural development: towards a negotiation approach. Dev Chang 31: 931-959

Lopez-Ridaura S, Masera O, Astier M (2002) Evaluating the sustainability of complex socio-environmental systems. The MESMIS framework. Ecol Indic 2:135-148

Meul M, Van Passel S, Nevens F, Dessein J, Rogge E, Mulier A, Van Hauwermeiren A (2008) MOTIFS: a monitoring tool for integrated farm sustainability. Agron Sust Dev 28:321-332

Meynard JM, Cerf M, Guichard L, Jeuffroy MH, Makowski D (2002) Which decision support tools for the environmental management of nitrogen. Agron J 22:817-829

Nolot J, Debaeke P (2003) Principes et outils de conception, conduite et évaluation de systèmes de culture. Cah Agric 12:387-400

Rossing WAH, Meynard JM, van Ittersum MK (1997) Model-based explorations to support development of sustainable farming systems: case studies from France and the Netherlands. Eur J Agron 7:271-283

Sadok W, Angevin F, Bergez JE, Bockstaller C, Colomb B, Guichard L, Reau R, Messéan A, Doré T (2009) MASC, a qualitative multiattribute decision model for ex ante assessment of the sustainability of cropping systems. Agron Sust Dev 29:447-461

Stein A, Riley J, Halberg N (2001) Issues of scale for environmental indicators. Agric Ecosyst Environ 87:215-232

Sterk B, Van Ittersum MK, Leeuwis C, Wijnands FG (2007) Prototyping and farm system modeling - partners on the road towards more sustainable farm systems? Eur J Agron 26:401-409

Van der Werf HMG, Zimmer C (1998) An indicator of pesticide environmental impact based on a fuzzy expert system. Chemosphere 36:2225-2249

Veldkamp A, Van Altvorst AC, Eweg R, Jacobsen E, Van Kleef A, Van Latesteijn H, Mager S, Mommaas H, Smeets PJAM, Spaans L, Van Trijp JCM (2009) Triggering transitions towards sustainable development of the Dutch agricultural sector: TransForum's approach. Agron Sust Dev 29:87-96

Vereijken P (1997) A methodical way of prototyping integrated and ecological arable farming systems (I/EAFS) in interaction with pilot farms. Eur J Agron 7:235-250

Walker B, Holling CS, Carpenter SR, Kinzig A (2004) Resilience, adaptability and transformability in social-ecological systems. Ecol Soc 9(2):5 